\title{
Current Overview of Surgical Options for Female Stress Urinary Incontinence
}

\author{
Aram Kim ${ }^{1}$, Sehwan Kim², Hyeong Gon Kim ${ }^{1}$ \\ ${ }^{1}$ Department of Urology, KonKuk University Medical Center, KonKuk University School of Medicine, Seoul, Korea \\ ${ }^{2}$ Department of Biomedical Engineering, Beckman Laser Institute Korea, School of Medicine, Dankook University, Cheoan, Korea
}

Stress urinary incontinence (SUI) is a highly prevalent health condition that significantly impacts the quality of life. Traditional methods of treatment for SUI, such as pubovaginal sling and Burch colposuspension, have been replaced by the midurethral sling because of its high efficacy, low complication and morbidity rates, and short learning curve. Although multiple behavior$\mathrm{al}$ and operative treatments exist, midurethral slings are the gold standard for the treatment of SUI in women. However, several reports have raised concerns about complications caused by the synthetic mesh used in midurethral slings. Therefore, surgical treatment for SUI in women must be chosen with care, taking into account potential complications. Herein, we review the current safety issues pertaining to the use of meshes, the efficacy of traditional surgeries, old and new midurethral slings, and recent data comparing the efficacy and safety of different surgical options. This review is aimed at developing practical guidelines for choosing surgical options for women with SUI.

Keywords: Pubovaginal sling; Burch colposuspension; Midurethral slings; Mesh complication; Stress urinary incontinence

- Research Ethics: This research was supported by the Leading Foreign Research Institute Recruitment Program through the National Research Foundation of Korea (NRF) funded by the Ministry of Science and ICT (MSIT) (NRF-2018K1A4A3A02060572).

- Conflict of Interest: No potential conflict of interest relevant to this article was reported.

\section{INTRODUCTION}

Female stress urinary incontinence (SUI) is a condition that can cause significant distress to patients and occurs in approximately $20 \%$ of women, making it a major cause of reduced quality of life [1-3]. Therefore, timely diagnosis and appropriate treatment for SUI is critical.

Patients with SUI who do not show improvements with conservative treatment require surgical treatment. Nonoperative and conservative therapies should be provided as the first-line of management, but if SUI remains an issue, surgical treatment may be considered. Many surgical treatment methods have been reported for SUI [4]. Recent trends in patient-centered healthcare indicate the importance of understanding patient expectations, discomfort, and goal of treatment. The decision to perform surgery should be made only after a thorough discussion of the risks and benefits of each surgical option.

This review focuses on recent trends and the state of current surgical options for SUI treatment in women. To offer the appropriate treatment option, we must discern current information about mesh-related issues, review the data comparing the efficacy of traditional surgeries with that of midurethral slings, and meta-analyze results from the debate of superiority among midurethral slings. Accordingly, surgeons can develop a better
Corresponding author: Hyeong Gon Kim (iD https://orcid.org/0000-0002-5034-5299 Department of Urology, KonKuk University Medical Center, KonKuk University School of Medicine, 120-2 Neungdong-ro, Gwangjin-gu, Seoul 05030, Korea E-mail: khgsjh@kuh.ac.kr

Submitted: November 18, 2019 / Accepted after revision: January 3, 2020
This is an Open Access article distributed under the terms of the Creative Commons Attribution Non-Commercial License (https://creativecommons.org/licenses/by-nc/4.0/) which permits unrestricted non-commercial use, distribution, and reproduction in any medium, provided the original work is properly cited. 
understanding of surgical trends in female SUI.

\section{ISSUES OF MESH COMPLICATIONS}

\section{Introduction of Issues}

Although midurethral slings have been widely used for SUI since the mid-1990s, many recent studies have raised concerns about their long-term safety. Recent reports from the European Commission's Scientific Committee on Emerging and Newly Identified Health Risks and the U.S. Food and Drug Administration (FDA) have noted the side effects of the use of mesh for the treatment of pelvic organ prolapse (POP) and SUI [5].

In 2008, the U.S. FDA issued a Public Health Notification and Safety Communication after more than 1,000 transvaginal mesh-related complications were reported in the Manufacturer and User Device Experience database [5]. In 2011, an update to this notification strongly warned against the use of transvaginal mesh for POP repair, but no decisive claims were made for the use synthetic midurethral slings for SUI [6]. The U.S. FDA reclassified meshes used for POP repair as class III devices but did not do the same for midurethral slings. In 2014, the UK Medicines and Healthcare products Regulatory Agency (MHRA) showed that "from a regulatory perspective, the benefits of the use of these devices outweigh the risks" and that there was "no justification for the MHRA taking regulatory action to remove all of these devices from use in UK hospitals" [7].

While doctors are familiar with the distinctions between mesh surgery for POP and its use in midurethral slings, only a few patients understand the difference between POP and SUI surgeries. The U.S. FDA notification did not address synthetic midurethral slings directly, but patient perception of transvaginal mesh use was negatively affected. Moreover, the debate regarding complications from mesh use in midurethral slings attracted considerable attention from the media [8]. Media reports of negative perceptions of the use of mesh in midurethral slings might cause patients to refuse surgeries. These concerns and reports have led to a reduction in the use of midurethral slings worldwide and to a paradigm shift towards an official "withdrawal" of midurethral sling use in the UK since 2018.

Because of the controversy around using mesh, the Society of Urodynamics and Female Pelvic Medicine and Urogenital Reconstruction (SUFU), the American Urogynecologic Society (AUGS), the American Urological Association (AUA), and the International Continence Society (ICS) have published unambiguous statements supporting the use of synthetic midurethral slings for SUI. These groups published a statement claiming that a clear distinction should be made between synthetic midurethral slings and vaginal mesh for POP repair, supporting the use of mesh in midurethral slings for women with SUI based on comprehensive evidence. The statement recommended that surgeons with limited experience in the placement and revision of synthetic midurethral slings be encouraged to refer to trained surgeons [9]. Additionally, the European Commission reported that "synthetic sling SUI surgery is an accepted procedure with proven efficacy and safety in the majority of patients with moderate to severe SUI when used by an experienced and appropriately trained surgeon" [10].

\section{Recent Trends of SUI Surgeries in the Era of Mesh-Related Issues}

Several reports have revealed a reduction in the use of midurethral slings because of negative public perception after an increased number of complications. One study revealed an overall decrease in the number of midurethral slings placed after the notification update from the U.S. FDA in 2011. From June 2010 to June 2014, the proportion of patients who underwent midurethral sling placement for SUI showed an overall decrease [11]. This decline was mainly attributed to the U.S. FDA notification released in July 2011 and the subsequent rejection by patients undergoing procedures using synthetic mesh.

One study showed a decline in synthetic midurethral sling use during a similar time period despite the release of the updated 2011 FDA notification (which did not address synthetic mesh use for SUI surgery). However, they noted that the use of midurethral slings was re-emerging after the release of the AUA/ICS/AUGS/SUFU position statement "a clear distinction should be made between synthetic midurethral slings and vaginal mesh for POP repair, supporting the use of mesh of midurethral slings in women with SUI based on a comprehensive evidence" [12].

\section{Time to Rethink Traditional SUI Surgeries: Clinical Outcomes of Traditional SUI Surgeries (Bulking Agent, Pubovaginal Sling, Burch Colposuspension)}

The AUA and SUFU guidelines regarding the treatment of SUI introduced 4 options of surgery which are as follows: bulking agents, autologous fascia pubovaginal sling, Burch colposuspension, and midurethral slings [13]. These guidelines generally recommend pubovaginal slings, Burch colposuspension, and midurethral slings as possible treatment options, each with its 
own risks and benefits, for women requiring surgery for SUI. Debate on the use of mesh in midurethral slings has increased the interest in traditional SUI surgery that use bulking agents, pubovaginal slings, and Burch colposuspension.

The injection of bulking agents into the urethra is a minimally invasive procedure that may increase urethral resistance. This procedure can be performed in the outpatient clinic under local anesthesia. Long-term and high-quality evidence of this option as first-line treatment is limited. A Cochrane review reported 14 studies, but they were not suitable for meta-analyses due to moderate quality [14]. According to the European Association of Urology (EAU) guidelines on SUI, bulking agents are not recommended for patients requiring definitive treatment for SUI [15]. Bulking agents can be useful in certain patients who are willing to accept a low reward based on low risk. Compared to other surgeries, bulking agents had higher objective recurrence rates but lower rates of voiding dysfunction [16]. Bulking agents may therefore be most appropriate for women who prefer a minimally invasive office procedure [17].

In the 1980s, McGuire and Lytton [18] introduced the pubovaginal sling, which involves harvesting a strip of the rectus fascia that is placed suburethrally through vaginal incision. The Stress Incontinence Surgical Efficacy Trial (2007) presented the results of the pubovaginal sling or Burch colposuspension in patients with SUI. After 2 years, the cure rate was superior with pubovaginal slings (66\%) than with Burch colposuspension (49\%) despite complication rates being higher for pubovaginal slings [19]. The AUA and EAU guidelines reported that the pubovaginal sling could be a good surgical option for women with SUI and showed that the sling was more effective than Burch colposuspension for the treatment of SUI but involved a higher rate of postoperative voiding dysfunction [19].

Although the surgery involves additional morbidities such as a longer operative time and wound complications from graft harvesting, the use of autologous tissue can avoid the issue of mesh complications. Pubovaginal slings can show consistent long-term efficacy in the treatment of primary and recurrent SUI; moreover, the sling has demonstrated superiority over bulking agents and Burch colposuspension. After the FDA notifications regarding mesh complications, use of the pubovaginal sling has shown a significant increase. Surgeons and patients who would rather avoid mesh complications may prefer the surgical option [20]. However, we must consider that use of the pubovaginal sling showed higher rates of voiding pressure, urinary tract infection, and voiding difficulty [21].
Burch colposuspension, which was first introduced in the 1960s, suspends the anterior vaginal wall to the Cooper's ligament. This option was the gold standard for many years and was performed via the open or laparoscopic approach. A Cochrane review involving more than 5,000 patients reported that the overall success rate was $85 \%$ ( 1 year) and that $70 \%$ of women experienced vaginal dryness for 5 years after surgery [22]. Recently, Conrad et al. reported that $90 \%$ of patients who underwent Burch colposuspension showed successful treatment with a mean follow-up of 50 months (13-89 months). They defined successful treatment as a subjective cure or significant improvement of SUI [23].

EAU guidelines recommend the use of Burch colposuspension if midurethral slings cannot be considered [15]. It remains a good option for female patients with SUI who wish to avoid the complications of fascia harvesting and/or mesh complications, especially if undergoing a simultaneous abdominal surgery. The EAU guidelines strongly recommend informing patients about the longer operation time, hospital stay, and recovery period [24]. Hemorrhage, de novo urgency, bladder perforation, and POP can occur during surgery. Moreover, suspension of the urethrovesical junction and subsequent alteration of the anterior vaginal wall might induce POP; in fact, several studies showed a 7\%-66\% estimated incidence of POP following the procedure [25].

\section{HOW CAN WE CHOOSE THE MOST APPROPRIATE SURGICAL METHOD FOR SUI?}

\section{Traditional Surgeries and Midurethral Slings}

In 2017, a systematic review of 28 randomized controlled trials (RCTs) compared the outcomes of the pubovaginal sling, Burch colposuspension, tension-free vaginal tape (TVT), and transobturator tape (TOT). The outcomes indicated that TVT/TOT and pubovaginal sling use had similar success rates, whereas TVT/TOT showed better success rates than Burch colposuspension. The pubovaginal sling resulted in a higher 5-year satisfaction rate than Burch colposuspension, but its usage decreased after the introduction of midurethral slings [26].

Pubovaginal slings have been used for many years with reported success rates of about $90 \%$ after 3-15 years of follow-up, and have similar short-term outcomes as midurethral slings [27]. However, compared to the midurethral sling, this procedure may have an additional morbidity associated with fascia harvesting, which should be explained during preoperative 
counseling [28]. Importantly, midurethral slings do not require fascia harvesting, which leads to a reduction in surgical time and morbidity

Burch colposuspension is another option for patients who wish to avoid mesh complications. This technique can be used in combination with open or minimally invasive abdominopelvic surgery, such as hysterectomy or sacrocolpopexy. However, the one large RCT that compared 2-year outcomes of Burch colposuspension and pubovaginal sling showed that the pubovaginal sling had lower re-treatment rates than did Burch colposuspension ( $4 \%$ vs. $13 \%$ ), and patient satisfaction in the pubovaginal sling group continued to be superior at the 5-year follow-up (83\% vs. $73 \%, \mathrm{P}=0.04)[19,29]$.

\section{TVT, TOT, and Single-Incision Mini-Slings Introduction of old and new midurethral slings}

Midurethral slings have become the standard surgical treatment because of its minimal invasiveness and good efficacy in SUI [30]. Currently, this surgical method is definitively the most common option for SUI. In 1996, Ulmsten et al. [31] introduced the TVT which used the retropubic space for mesh positioning. The TVT is inserted with a "bottom to top" approach through a suburethral incision in the anterior wall of the vagina to the anterior abdominal wall. The suprapubic arch (SPARC, American Medical Systems, Minnetonka, MN, USA) sling system was a "top-down" retropubic sling with complications similar to the "bottom-up" design of the TVT. However, it was not commonly used and has since been withdrawn from the market. This withdrawal is supported by the Cochrane review, which assessed both the bottom-up and top-down approaches and revealed the bottom-up approach to be superior. They reported lower subjective and objective cure rates and higher rates of bladder perforation, tape erosion, and voiding dysfunction when SPARC was used [32].

On the other hand, TOT was described later when Delorme performed an "outside-in" approach and subsequently an "inside-out" procedure [33]. TOT was developed in an effort to provide a sling that could avoid passage through the retropubic space and potentially decrease complication rates.

Due to several complications from midurethral sling use, new surgical methods were introduced for the treatment of SUI in women. Single-incision mini-slings can overcome the complications of conventional midurethral slings, and the new methods use a short tape through a single vaginal incision; therefore, the tape does not pass through the retropubic or ob- turator spaces. Based on the procedure and device of the minisling, single-incision mini-slings can reduce the chance of various complications, such as nerve or vessel injury and groin pain. However, some single-incision mini-slings, such as the TVT-Secur (Gynecare TVT Secur, Gynecare, Ethicon Inc., Somerville, MA, USA) and Mini-tape, have been withdrawn from the market due to major complications.

\section{Comparison of efficacy between TVT, TOT, and single-incision mini-sling}

Debate persists about the efficacy of TVT and TOT, although many guidelines recommend midurethral slings as a standard option for SUI. The AUA and EAU do not prefer TVT over TOT and have stated that they have equivalent outcomes [15, 34]. The International Consultation of Incontinence (ICI) has also stated that there is insufficient evidence to draw conclusions about the long-term efficacy of TVT versus TOT.

However, several studies have reported different long-term efficacies of TVT as compared to TOT. Kenton et al. [35] showed that the cure rate was $7.9 \%$ greater in the TVT group than in the TOT group 5 years after surgery. One meta-analysis reported that TVT had a better cure rate than TOT in a general cohort of women with SUI during a follow-up of at least 1 year [36]. A critical issue, however, is that such differences in cure rates are minimal and marginally clinically relevant [37].

The AUA acknowledges the lack of data but has stated that preliminary data appear to favor the durability of TVT. Although the EAU found that while TVT and TOT had equivalent patient-reported outcomes after 5 years, TVT had higher objective and subjective cure rates after 8 years (Level 1b) [35]. The National Institute for Health and Care Excellence (NICE) recently updated their guidelines to recommend against TOT use unless there is a specific clinical circumstance that necessitates the avoidance of the retropubic space. This was based on a systemic review that showed that TOT was worse than TVT in terms of subjective outcomes 1 year after surgery [38].

One previous meta-analysis revealed that conventional midurethral slings had significantly better objective cure rates than single-incision mini-slings [39]. After reporting the outcomes, some single-incision mini-slings, such as the TVT-Secur and Mini-tape, have been withdrawn from the market due to severe complications and poor efficacy. The updated meta-analysis regarding the withdrawal of the mini-slings showed corrected outcomes including that conventional midurethral slings have a superior long-term efficacy to single-incision mini-slings [40]. 
The AUA and ICI have given grade B recommendations for new slings to be offered as treatments for uncomplicated SUI but also advise warning patients about the immaturity of evidence regarding their efficacy and safety [40]. Single-incision mini-slings may be appropriate for some women who desire less short-term pain than that resulting from conventional midurethral slings [40].

\section{Application in high risk cases: intrinsic sphincter deficiency, obesity, recurrent SUI, and concomitant POP}

Based on clinically marginal differences in efficacy between TVT and TOT, another meta-analysis using a different cohort of selected patients with a high risk of recurrence after SUI surgery identified risk factors that included intrinsic sphincter deficiency (ISD), obesity, concomitant POP, and recurrent SUI after initial surgery [41]. Authors of the meta-analysis included 28 studies that used a stress test to evaluate the objective cure rate; the mean follow-up period in these studies was 26.9 months (range, 6-72 months). The meta-analysis showed that the overall objective cure rates of TVT and TOT in the selected cases were $87.9 \%$ and $70.8 \%$, respectively, and the objective cure rates in SUI patients with ISD were $85.8 \%$ and $60.1 \%$, respectively. In obese SUI patients, the objective cure rates of TVT and TOT were $94.9 \%$ and $82 \%$, respectively. The objective cure rates of TVT and TOT with cosurgery (POP repair and midurethral sling) were $88.2 \%$ and $82.6 \%$, respectively, while those of repeat midurethral slings in recurrent cases of SUI were $82.2 \%$ and $65.8 \%$, respectively. These results indicate that TVT is definitively superior than TOT in patients at higher risk of recurrence [41].

\section{Safety of TVT versus TOT}

A 2017 Cochrane review of midurethral sling safety showed a higher risk of complications in TVT than in TOT, including bladder perforation as well as visceral and vascular injuries. The incidence of suprapubic pain was lower in TOT $(0.8 \%)$ than in TVT (2.9\%) [37]. In one RCT using long-term follow-up data of a large cohort, there were reports of adverse events with the 2 surgical options. In the observational period, $10 \%$ of patients $(n=40)$ experienced 52 nonserious adverse events and 6 serious adverse events. There was no difference between the 2 surgical options in the proportion of patients who had at least one adverse event. All 6 serious adverse events that required intervention were in the TVT group. In postoperative years 3-5, there were 7 mesh-related problems (3 in TVT and 4 in TOT) [35].
In a meta-analysis of SUI cases with complications, the authors found different outcomes. Importantly, there were no significant differences in the overall complication rate between TVT and TOT in patients at high risk of recurrence, except for bladder perforation. Bladder perforation was unique to TVT whereas vaginal perforation was unique to TOT, neither of which was considered a critical problem [41].

Another meta-analysis reported the specific types of complications arising from TVT and TOT use. The authors showed that the complications resulting from TVT use differ from those from TOT use. The risk of bladder perforation and bleeding was higher in TVT than in TOT. However, the need for blood transfusions was reported in only one study. TOT involved more vaginal perforations and postoperative neurological symptoms. The risk of mesh problems and postoperative urinary retention did not differ between the 2 surgical options [36]. Thus, the complications resulting from midurethral slings may not be clinically relevant when experienced surgeons perform the surgeries. Bladder and vaginal perforations after TVT/ TOT can be treated easily with tape repositioning.

\section{OTHER OPTIONS: ARTIFICIAL URINARY SPHINCTER PLACEMENT OR ADJUSTABLE SLING}

The outcomes of midurethral slings in recurrent SUI or ISD are not as promising; therefore, novel surgical tools have focused on complicated SUI cases.

\section{Artificial Urinary Sphincter Placement}

Among the options, the EAU guidelines emphasize the possible role of external compression devices, such as artificial urinary sphincter placement [42]. In France, artificial urinary sphincter placement is commonly used for SUI in women [43]. Moreover, the surgery can be performed in women with recurrent SUI. According to several data, surgery may provide excellent functional outcomes in women with recurrent SUI. Revaux et al. [44] performed open surgery and reported the functional outcomes in female patients with ISD and recurrent SUI. Overall continence was achieved in $68 \%$ of patients. Twelve percent of patients showed moderate incontinence ( 1 or 2 pads/day) and $14 \%$ patients continued to show severe incontinence (3 or 4 pads/day). The continence rates at 5 and 10 years were $87.5 \%$ and $63 \%$, respectively. Intraoperative injuries were encountered in 5 women (10\%), which included urethral injuries $(\mathrm{n}=3,6 \%)$ and vaginal injuries $(n=2,4 \%)$. Moreover, they reported an 
$18 \%$ rate of device explantation, a major postoperative complication within the mean follow-up period of 8 years. The explantation-free survival rates at 5 and 10 years were $90 \%$ and $80 \%$, respectively.

Clinical outcomes of robot-assisted artificial urinary sphincter placement were reported by surgeons in France. Biardeau et al. [45] reported an $87.5 \%$ continence rate after a mean followup of 17.6 months among women who underwent multiple failed SUI surgeries. While the durability of surgery has been demonstrated by several series in male patients, further confirmatory data are needed to establish the outcomes of anti-incontinence surgery in women with SUI.

In a recent systematic review, the authors found that evidence supporting the use of an artificial urinary sphincter is scarce and of poor quality, comprising only highly biased case series [46]. Moreover, dexterity and cognitive function of patients should be carefully assessed prior to artificial urinary sphincter placement.

Given the complexity of these cases and the risk of complications and need for surgical revision, this surgery should be performed by experienced and high-volume surgeons only. The EAU advises warning women that while a cure is possible, there is a high risk of complications, mechanical failure, or need for explantation, even at expert centers. The NICE guidelines recommend against the use of the procedure for treating SUI in women unless a previous surgery failed. In cases of nonneurogenic SUI, artificial urinary sphincter placement has a limited role because of a lack of long-term follow-up data. It should only be used for recurrent and refractory cases and performed by experienced surgeons.

\section{Readjustable Midurethral Sling (the Remeex System)}

It can be difficult to achieve appropriate tension with TVT and TOT, and moreover, the tension cannot be adjusted after surgery. Furthermore, acute urinary retention or persistent urine leakage can occur due to inappropriate tension. The readjustable midurethral sling (Remeex system, Neomedic International, Terrassa, Spain) uses an adjustable device that allows surgeons to regulate tension intra- and postoperatively, which can decrease the complication rate. Due to its adjustability, the Remeex system can be used for women with complicated SUI, those who experience recurrent SUI after a previous surgery for anti-incontinence, and those who have ISD or detrusor underactivity [47].

In one study, after a 60-month follow-up, the cure rate was
$86 \%$, with $7 \%$ of patients undergoing readjustment under local anesthesia [48]. One long-term outcome (median follow-up, 89 months) of the Remeex system in ISD and recurrent SUI cases were reported in 2018 [49]. The initial outcomes of that study revealed an overall cure rate of $87 \%$. When a larger number of cases was analyzed for an extended follow-up period, the continence rate fell to $71.7 \%$, without a significant difference between ISD (68.2\% vs. $77.1 \%)$ and recurrent SUI (75.7\% vs. $84.4 \%)$. The ability to readjust tension during follow-up was fully utilized, as $42.9 \%$ of the patients took advantage of this treatment option and many patients (34.6\%) required only one readjustment. The complication rate increased to $29 \%$ at a longer follow-up. Of note, the complications were mainly (25.4\%) Clavien II; 3 cases of infection required additional surgery to remove the device and to perform urethroplasty, showing a 3.4\% Clavien-Dindo Classification III rate.

The Remeex system has strong advantages in the management of patients with recurrent SUI, ISD, or voiding dysfunction such as an underactive bladder. However, clinical trials and evidence evaluating the efficacy of the Remeex system for recurrent SUI and ISD are still lacking. Effort should be directed to the development of such studies to achieve the highest level of evidence to recommend this procedure as a standard of care. This procedure is not included in any current guidelines.

\section{CONCLUSIONS}

Several treatment options are available for the surgical management of SUI in women. Although pubovaginal sling and Burch colposuspension were the gold standards historically, most patients are currently offered midurethral slings. Almost all guidelines recommended midurethral slings to women with SUI as the first option for surgery, and current data overwhelmingly indicate a better efficacy of TVT as compared to TOT. Surgeons should know the risks and benefits of the different options for SUI to identify a tailored surgical option for each woman with SUI.

\section{AUTHOR CONTRIBUTION STATEMENT}

- Conceptualization: $A R K, H G K, S H K$

- Formal Analysis: $A R K, H G K$

- Investigation: $A R K, H G K$

- Methodology: ARK, HGK

- Project Administration: ARK, HGK, SHK 
-Writing-Original Draft: $A R K, H G K, S H K$

-Writing-Review \& Editing: ARK, HGK, SHK

\section{REFERENCES}

1. Aponte MM, Shah SR, Hickling D, Brucker BM, Rosenblum N, Nitti VW. Urodynamics for clinically suspected obstruction after anti-incontinence surgery in women. J Urol 2013;190:598-602.

2. James MB, Theofanides MC, Sui W, Onyeji I, Badalato GM, Chung DE. Sling procedures for the treatment of stress urinary incontinence: comparison of national practice patterns between urologists and gynecologists. J Urol 2017;198:1386-91.

3. Kosilov K, Kuzina I, Loparev S, Gainullina Y, Kosilova L, Prokofyeva A. Influence of the short-term intake of high doses of solifenacin and trospium on cognitive function and health-related quality of life in older women with urinary incontinence. Int Neurourol J 2018;22:41-50.

4. Bent AE, Foote J, Siegel S, Faerber G, Chao R, Gormley EA. Collagen implant for treating stress urinary incontinence in women with urethral hypermobility. J Urol 2001;166:1354-7.

5. Daneshgari F. Words of wisdom. Re: FDA public health notification: serious complications associated with transvaginal placement of surgical mesh in repair of pelvic organ prolapse and stress urinary incontinence. Eur Urol 2009;55:1235-6.

6. Murphy M, Holzberg A, van Raalte H, Kohli N, Goldman HB, Lucente $\mathrm{V}$, et al. Time to rethink: an evidence-based response from pelvic surgeons to the FDA Safety Communication: "UPDATE on Serious Complications Associated with Transvaginal Placement of Surgical Mesh for Pelvic Organ Prolapse”. Int Urogynecol J 2012;23:5-9.

7. Brown J, King J. Age-stratified trends in 20 years of stress incontinence surgery in Australia. Aust N Z J Obstet Gynaecol 2016;56: 192-8.

8. Nager CW. Midurethral slings: evidence-based medicine vs the medicolegal system. Am J Obstet Gynecol 2016;214:708.e1-5.

9. Abdel-Fattah M, MacLennan G, Kilonzo M, Assassa RP, McCormick K, Davidson T, et al. The SIMS trial: adjustable anchored single-incision mini-slings versus standard tension-free midurethral slings in the surgical management of female stress urinary incontinence. A study protocol for a pragmatic, multicentre, non-inferiority randomised controlled trial. BMJ Open 2017;7:e015111.

10. Blaivas JG, Purohit RS, Benedon MS, Mekel G, Stern M, Billah M, et al. Safety considerations for synthetic sling surgery. Nat Rev Urol 2015;12:481-509.

11. Chughtai BI, Elterman DS, Vertosick E, Maschino A, Eastham JA, Sandhu JS. Midurethral sling is the dominant procedure for female stress urinary incontinence: analysis of case logs from certifying American Urologists. Urology 2013;82:1267-71.

12. Palmerola R, Peyronnet B, Rebolos M, Khan A, Sussman RD, Escobar $\mathrm{C}$, et al. Trends in stress urinary incontinence surgery at a tertiary center: midurethral sling use following the AUGS/SUFU position statement. Urology 2019 Sep;131:71-76.

13. Kobashi KC, Albo ME, Dmochowski RR, Ginsberg DA, Goldman HB, Gomelsky A, et al. Surgical treatment of female stress urinary incontinence: AUA/SUFU guideline. J Urol 2017;198:875-83.

14. Viereck V, Gamper M. Re: Kirchin V, Page T, Keegan PE, Atiemo KO, Cody JD, McClinton S, Aluko P. Urethral injection therapy for urinary incontinence in women. Cochrane Database Syst Rev 2017;7:CD003881.

15. Lucas MG, Bosch RJ, Burkhard FC, Cruz F, Madden TB, Nambiar AK, et al. EAU guidelines on surgical treatment of urinary incontinence. Actas Urol Esp 2013;37:459-72.

16. Kirchin V, Page T, Keegan PE, Atiemo K, Cody JD, McClinton S. Urethral injection therapy for urinary incontinence in women. Cochrane Database Syst Rev 2012;:CD003881.

17. Kowalik CG, Dmochowski RR, De EJB. Surgery for female SUI: The ICI algorithm. Neurourol Urodyn 2019;38 Suppl 4:S21-7.

18. Mcguire EJ, Lytton B. Pubovaginal sling procedure for stress incontinence. J Urol 1978;119:82-4.

19. Albo ME, Richter HE, Brubaker L, Norton P, Kraus SR, Zimmern $\mathrm{PE}$, et al. Burch colposuspension versus fascial sling to reduce urinary stress incontinence. N Engl J Med 2007;356:2143-55.

20. Rac G, Younger A, Clemens JQ, Kobashi K, Khan A, Nitti V, et al. Stress urinary incontinence surgery trends in academic female pelvic medicine and reconstructive surgery urology practice in the setting of the food and drug administration public health notifications. Neurourol Urodyn 2017;36:1155-60.

21. Kraus SR, Lemack GE, Richter HE, Brubaker L, Chai TC, Albo $\mathrm{ME}$, et al. Changes in urodynamic measures two years after Burch colposuspension or autologous sling surgery. Urology 2011;78: 1263-8.

22. Dean N, Ellis G, Herbison GP, Wilson D, Mashayekhi A. Laparoscopic colposuspension for urinary incontinence in women. Cochrane Database Syst Rev 2017;7:CD002239.

23. Conrad DH, Pacquee S, Saar TD, Walsh C, Chou D, Rosen D, et al. Long-term patient-reported outcomes after laparoscopic Burch colposuspension. Aust N Z J Obstet Gynaecol 2019;59:850-5.

24. Lapitan MCM, Cody JD, Mashayekhi A. Open retropubic colposuspension for urinary incontinence in women. Cochrane Database Syst Rev 2017;7:CD002912.

25. Kwon CH, Culligan PJ, Koduri S, Goldberg RP, Sand PK. The de- 
velopment of pelvic organ prolapse following isolated Burch retropubic urethropexy. Int Urogynecol J Pelvic Floor Dysfunct 2003;14:321-5; discussion 325.

26. Fusco F, Abdel-Fattah M, Chapple CR, Creta M, La Falce S, Waltregny $\mathrm{D}$, et al. Updated systematic review and meta-analysis of the comparative data on colposuspensions, pubovaginal slings, and midurethral tapes in the surgical treatment of female stress urinary incontinence. Eur Urol 2017;72:567-91.

27. Tincello DG, Armstrong N, Hilton P, Buckley B, Mayne C. Surgery for recurrent stress urinary incontinence: the views of surgeons and women. Int Urogynecol J 2018;29:45-54.

28. Chaikin DC, Rosenthal J, Blaivas JG. Pubovaginal fascial sling for all types of stress urinary incontinence: long-term analysis. J Urol 1998;160:1312-6.

29. Brubaker L, Richter HE, Norton PA, Albo M, Zyczynski HM, Chai TC, et al. 5-year continence rates, satisfaction and adverse events of burch urethropexy and fascial sling surgery for urinary incontinence. J Urol 2012;187:1324-30.

30. Withington J, Hirji S, Sahai A. The changing face of urinary continence surgery in England: a perspective from the Hospital Episode Statistics database. BJU Int 2014;114:268-77.

31. Ulmsten U, Henriksson L, Johnson P, Varhos G. An ambulatory surgical procedure under local anesthesia for treatment of female urinary incontinence. Int Urogynecol J Pelvic Floor Dysfunct 1996;7:81-5; discussion 85-6.

32. Ogah J, Cody JD, Rogerson L. Minimally invasive synthetic suburethral sling operations for stress urinary incontinence in women. Cochrane Database Syst Rev 2009:CD006375.

33. Bailey GC, Blackburne A, Ziegelmann MJ, Lightner DJ. Outcomes of surgical management in patients with stress urinary incontinence and/or neovesicovaginal fistula after orthotopic neobladder diversion. J Urol 2016;196:1478-83.

34. Ford AA, Rogerson L, Cody JD, Aluko P, Ogah JA. Mid-urethral sling operations for stress urinary incontinence in women. Cochrane Database Syst Rev 2017;7:CD006375..

35. Kenton K, Stoddard AM, Zyczynski H, Albo M, Rickey L, Norton P, et al. 5-year longitudinal followup after retropubic and transobturator mid urethral slings. J Urol 2015;193:203-10.

36. Seklehner S, Laudano MA, Xie D, Chughtai B, Lee RK. A metaanalysis of the performance of retropubic mid urethral slings versus transobturator mid urethral slings. J Urol 2015;193:909-15.

37. Fusco F, Abdel-Fattah M, Chapple CR, Creta M, La Falce S, Waltregny D, et al. Updated systematic review and meta-analysis of the comparative data on colposuspensions, pubovaginal slings, and midurethral tapes in the surgical treatment of female stress urinary incontinence. Eur Urol 2017;72:567-91.

38. Brazzelli M, Javanbakht M, Imamura M, Hudson J, Moloney E, Becker F, et al. Surgical treatments for women with stress urinary incontinence: the ESTER systematic review and economic evaluation. Health Technol Assess 2019;23:1-306.

39. Kim A, Kim MS, Park YJ, Choi WS, Park HK, Paick SH, et al. Clinical outcome of single-incision slings, excluding TVT-Secur, vs standard slings in the surgical management of stress incontinence: an updated systematic review and meta-analysis. BJU Int 2019;123: 566-84.

40. Mostafa A, Lim CP, Hopper L, Madhuvrata P, Abdel-Fattah M. Single-incision mini-slings versus standard midurethral slings in surgical management of female stress urinary incontinence: an updated systematic review and meta-analysis of effectiveness and complications. Eur Urol 2014;65:402-27.

41. Kim A, Kim MS, Park YJ, Choi WS, Park HK, Paick SH, et al. Retropubic versus transobturator mid urethral slings in patients at high risk for recurrent stress incontinence: a systematic review and meta-analysis. J Urol 2019;202:132-42.

42. Nambiar AK, Bosch R, Cruz F, Lemack GE, Thiruchelvam N, Tubaro A, et al. EAU guidelines on assessment and nonsurgical management of urinary incontinence. Eur Urol 2018;73:596-609.

43. Cour F, Le Normand L, Lapray JF, Hermieu JF, Peyrat L, Yiou R, et al. Insuffisance sphinctérienne et incontinence urinaire de la femme [Intrinsic sphincter deficiency and female urinary incontinence]. Prog Urol 2015;25:437-54.

44. Revaux A, Rouprêt M, Seringe E, Misraï V, Cour F, Chartier-Kastler $\mathrm{E}$. Is the implantation of an artificial urinary sphincter with a large cuff in women with severe urinary incontinence associated with worse perioperative complications and functional outcomes than usual? Int Urogynecol J 2011;22:1319-24.

45. Biardeau X, Rizk J, Marcelli F, Flamand V. Robot-assisted laparoscopic approach for artificial urinary sphincter implantation in 11 women with urinary stress incontinence: surgical technique and initial experience. Eur Urol 2015;67:937-42.

46. Peyronnet B, O'Connor E, Khavari R, Capon G, Manunta A, Allue $\mathrm{M}$, et al. AMS-800 Artificial urinary sphincter in female patients with stress urinary incontinence: a systematic review. Neurourol Urodyn 2019;38 Suppl 4:S28-41.

47. Chung JW, Yoo ES. Efficacy and safety of a readjustable midurethral sling (Remeex system) for stress urinary incontinence with female voiding dysfunction. Investig Clin Urol 2017;58:127-33.

48. Giberti C, Gallo F, Cortese P, Schenone M. The suburethral tension adjustable sling (REMEEX system) in the treatment of female urinary incontinence due to 'true' intrinsic sphincter deficiency: re- 
TJ Kim, et al. • Surgical Options for Female Stress Urinary Incontinence

sults after 5 years of mean follow-up. BJU Int 2011;108:1140-4.

49. Errando-Smet C, Ruiz CG, Bertrán PA, Mavrich HV. A re-adjustable sling for female recurrent stress incontinence and intrinsic sphincteric deficiency: Long-term results in 205 patients using the Remeex sling system. Neurourol Urodyn 2018;37:1349-55. 